\title{
Rosuvastatin Loaded Nanostructured Lipid Carrier: For Enhancement of Oral Bioavailability
}

\author{
Anand Panchakshari Gadad, Swetha Gangadhar Tigadi, Panchaxari Mallappa Dandagi, Vinayak \\ Shivamurthi Mastiholimath and Uday Baburao Bolmal
}

KLE University's College of Pharmacy, Department of Pharmaceutics, JNMC Campus, Belagavi-590010, Karnataka, INDIA.

\begin{abstract}
Rosuvastatin is a lipid lowering agent, which has low solubility and low bioavailability of $20 \%$ with oral administration. Therefore the present study was undertaken to improve solubility and bioavailability of Rosuvastatin by formulating it into Nano structured lipid carriers (NLCs) by using stearic acid and Compritol ATO 888 as solid-lipid, Oleic acid as liquid-lipid and Poloxamer 188 as a surfactant. Rosuvastatin loaded NLCs were prepared by high shear homogenisation followed by Ultra sonication technique. In this study two solid lipids (stearic acid and Compritol ATO 888) were compared with liquid lipid in different concentration in order to select suitable solid liquid lipid for Rosuvastatin to achieve particle size in nano range. The prepared NLCs were evaluated for particle size and size distribution, Poly dispersity index, drug content, entrapment efficiency, zeta potential, In-vitro drug release, In-vivo bioavailability study in rat. The drug content for the formulation F1 to F8 was found to be in the range of 83.18 to $96.59 \%$. The formulation F3 was optimised based on the mean particle size, poly dispersity index, entrapment efficiency and zeta potential which showed $213.26 \mathrm{~nm}, 0.22,89.1 \%$ and -50.6 respectively. Transmission electron microscopy (TEM) studies on formulation F3 revealed that all the particles were within the nano size range. Formulation F3 showed In-vitro drug release of $76.22 \%$ at the end of $12 \mathrm{hrs}$ with a sustained release. HPLC method was developed for determination of Rosuvastatin calcium in rat plasma for bioavailability and pharmacokinetic evaluation. The relative bioavailability of NLC formulation F3 showed an enhanced bioavailability with two folds as compared to the marketed conventional tablet. The stability study was carried at $4^{\circ} \mathrm{C}$ with $65 \% \mathrm{RH}$ for 30 days showed no change in the particle size, entrapment efficiency and In-vitro drug release.
\end{abstract}

Key words: Rosuvastatin, Nano structured, Stearic acid, Compritol, Homogeniser.

\section{INTRODUCTION}

Oral route is the most preferred route for administration of drug as it offers greatest degree of patient compliance. But most of the drugs exhibit poor solubility, thus their oral delivery often results in low bioavailability. The newly emerging lipid based nano particles have been developed with the aim of enhancing bioavailability of drug by improving its dissolution and solubility. Nano structured lipid carrier (NLC) is second generation smarter drug carrier system having solid matrix at room temperature. ${ }^{1}$ NLCs are composed of biocompatible solid lipid matrices and liquid lipid which have different chemical structure from the solid lipid. ${ }^{2}$ NLC exhibit superior advantages over other colloidal carriers and thus, have been explored to more extent in pharmaceutical technology.

Rosuvastatin belongs to a class of medications called statins and is used as an adjunct to dietary therapy to treat primary Hyper-
Submission Date : 24-05-2016 Revision Date : :19-07-2016 Accepted Date : :24-08-2016

DOI: 10.5530/ijper.50.4.13 Correspondence:

A. P. Gadad,

KLE University's College of Pharmacy, Department of Pharmaceutics, JNMC Campus, Belagavi-590010, Karnataka, India.

Phone no: +91-9448309472 Fax: 08312472387

E-mail: gadadap@rediffmail. com

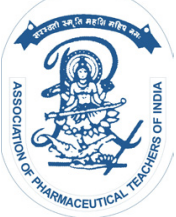

www.ijper.org 
lipidemia, mixed dyslipidemia and Hyper triglyceridemia. It is slightly soluble in water. It has low bioavailability of $20 \%$ and a half life of $19 \mathrm{hrs}$. It undergoes hepatic first pass metabolism. ${ }^{3}$

As per the literature study, it shows that high shear homogenisation is the rapid and easy method for formulation of NLCs and Emami J, (2012) prepared cholesterol Nano structured lipid carriers with various oleic acid content loaded with drug Paclitaxel by solvent Emulsification-diffusion method using a Taguchi Design. Particle size, zeta potential, entrapment efficiency, drug loading and release percent of NLCs were measured; Cytotoxicity studies indicate that PTX associated with the NLC is also effective in HT-29 cell lines and enters the cancer cells selectively through the LDL receptor endocytic pathway. ${ }^{4}$ When compared to other molecules of the same class, it shows high efficacy in the improvement of lipid profile, and, thanks to its non-cholesterol lowering actions (anti-inflammatory, antioxidant and antithrombotic), represents a crucial tool for cardiovascular primary and secondary prevention. ${ }^{5}$ Pharmacokinetic study on female albino Wistar rats showed 5.4-fold increase in relative bioavailability with NLC compared to active pharmaceutical ingredient suspension. Optimized NLC formulation also showed significant $(p<0.01)$ lipid lowering effect in hyper lipidemic rats. ${ }^{6}$ The present study was undertaken to develop Nano structured lipid carrier for Rosuvastatin with prospect of increasing its solubility and also enhancing oral bioavailability.

\section{MATERIALS AND METHODS}

\section{Materials}

Rosuvastatin a lipid lowering agent was received as a gift sample from Cadila Health Care Ltd, Goa, India. Compritol ATO 888 was procured from Gattefosse SAS, France. Stearic acid was obtained from Qualigens fine chemicals, Mumbai, India. Oleic acid was obtained from SD fine-Chem Ltd., Mumbai, India and Poloxamer 188 was obtained from Ozone international, Mumbai, India.

\section{Method}

Nano structured lipid carrier was prepared by high shear homogenization followed by Ultra sonication method. ${ }^{7}$ In this method, lipids were melted at temperature ten degrees above its melting point, then drug was added to the melted lipids. The lipid phase and aqueous were prepared separately. The dispersion was kept at the same temperature until it appeared optically clear. Surfactant solution was prepared by dissolving Poloxamer 188 in distilled water and heated to the same tempera- ture of lipid mixture. Hot surfactant solution was then added to lipid phase drop wise and stirred for $10 \mathrm{~min}$ on magnetic stirrer. The dispersion was further mixed using high shear homogenizer at $12000 \mathrm{rpm}$ for $30 \mathrm{~min}$ followed by Ultra sonication for $15 \mathrm{~min}$. The prepared formulations were stored at $4^{0} \mathrm{C}$ in a Refrigerator. The composition of NLCs F1 to F8 is given in Table 1.

\section{Particle size analysis and Poly dispersity index}

The mean particle size and Poly dispersity index of the formulations were measured by Dynamic Light Scattering Particle Size Analyser 8 (Nano trac 150 USA). The cell of the Nanotrac was cleaned and background was taken with Millipore water. $3 \mathrm{ml}$ of sample was placed in a cell and was scanned for six times to get an average reading of particle size and Polydispersity index.

\section{Drug content determination}

Drug loaded NLC equivalent to $1 \mathrm{mg}$ was first dissolved in $1 \mathrm{ml}$ methanol and was further diluted up to $10 \mathrm{ml}$ with phosphate buffer $\mathrm{pH} 6.8$ and stirred continuously for $2 \mathrm{hrs}$ and then final colloidal suspension was ultra centrifuged at 10,000 rpm for $30 \mathrm{~min}$. Supernant was taken, appropriate dilutions were made and measured spectro photometrically at $239.2 \mathrm{~nm}$ to get drug content. ${ }^{9}$

\section{Entrapment Efficiency determination}

The entrapment efficiency was determined by measuring the amount of drug entrapped in NLCs $10 \mathrm{~A}$ volume of $3 \mathrm{ml}$ of each drug loaded sample was taken in a micro centrifuge tube and centrifuged at 50,000 rpm at $25^{\circ} \mathrm{C}$ for $2 \mathrm{hr}$ using Sorval $\mathrm{mX} 150$ Micro-centrifuge (Thermo scientific, USA). The supernatant was collected; appropriate dilutions were made with phosphate buffer pH 6.8 and analyzed spectro photometrically at $239.2 \mathrm{~nm}$. The entrapment efficiency was calculated as follows:

$\%$ entrapment efficiency $=\frac{\begin{array}{c}\text { Total amount of drug }- \\ \text { Total amount of unbold drug }\end{array}}{\text { Total amount of drug }} \times 100$

\section{Zeta potential determination}

Zeta potential of suitably diluted NLCs was measured using zeta meter $3.0+$ (Uniton, Japan). Charge on NLCs and their mean zeta potential value with standard deviation of three measurements were obtained. ${ }^{11}$

\section{In vitro drug release}

The in vitro release of Rosuvastatin from different formulations was determined using the dialysis bag diffusion technique. ${ }^{12}$ An accurately weighed amount of NLC equivalent to $5 \mathrm{mg}$ of drug was transferred to a dialysis bag (Hi-media, Mumbai, India) with molecular 


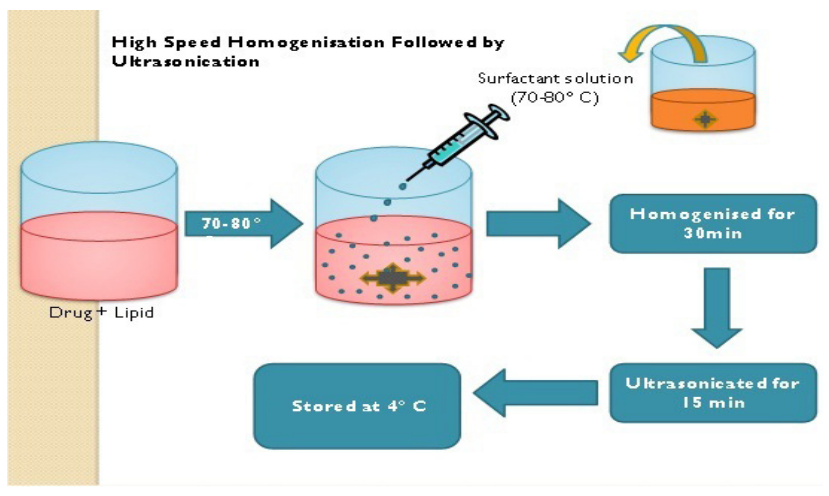

Figure 1: Schematic representation of the High shear homogenisation followed by Ultrasonication technique.

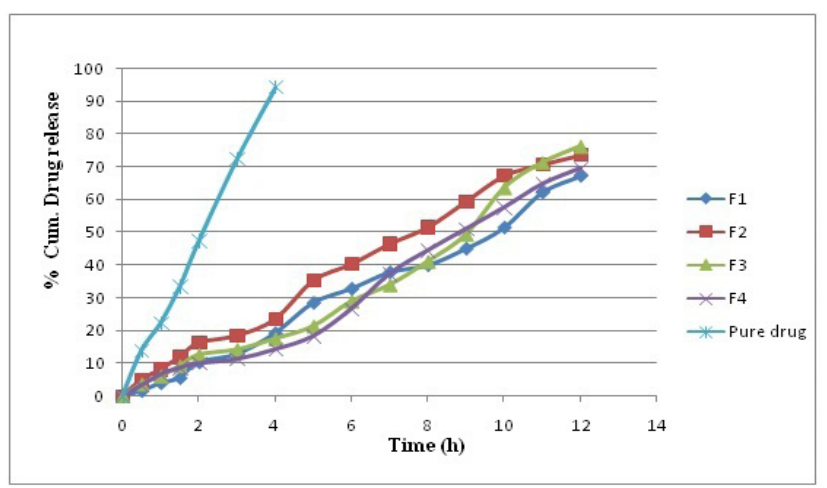

Figure 2: In vitro dissolution profile of the formulation F1 to F4 and pure drug.

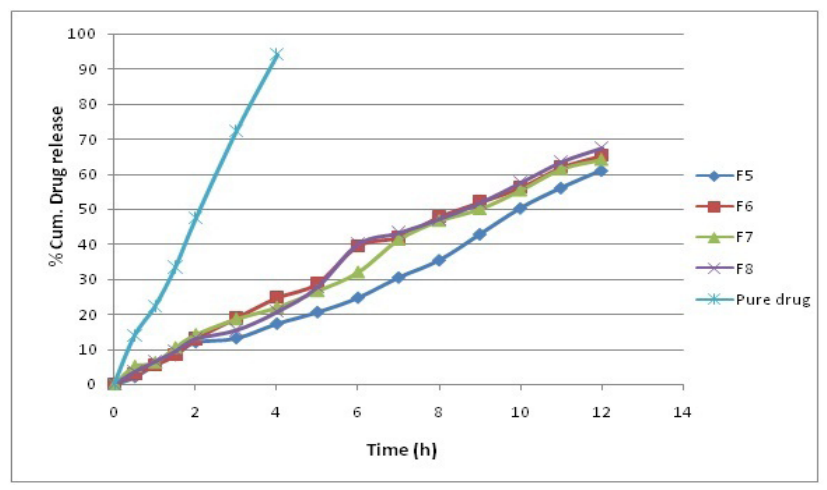

Figure 3: In vitro dissolution profile of the formulation F5 to F8 and pure drug.

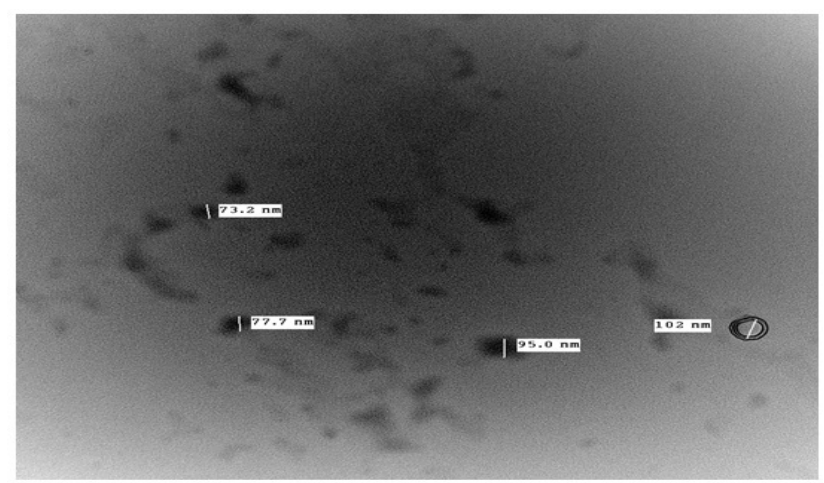

Figure 4: Transmission Electron microscopy of NLC Formulation F3.

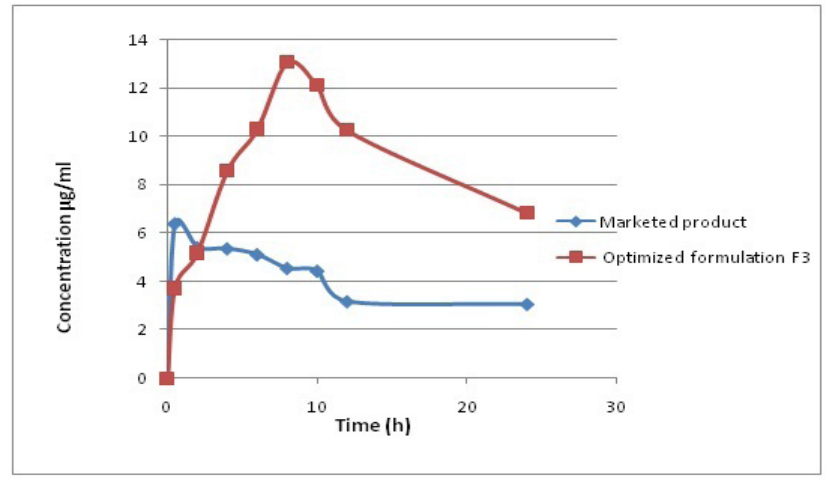

Figure 5: Comparative in-vivo release profile of Optimized formulation F3 and Marketed product by oral administration.

weight cut off 12,000 - 14,000 Dalton and sealed. The sealed bag was then suspended initially for $2 \mathrm{hrs}$ in USP Type II Apparatus containing $900 \mathrm{ml} 0.1 \mathrm{~N} \mathrm{HCl} \mathrm{pH} 1.2$ followed by phosphate buffer $\mathrm{pH} 6.8$ up to $12 \mathrm{hrs}$ at a constant speed of $50 \mathrm{rpm}$ at $37^{\circ} \mathrm{C} \pm 0.5^{\circ} \mathrm{C}$. Aliquots of $5 \mathrm{ml}$ of the sample were withdrawn at predetermined intervals from the receptor compartment and the same was replaced with fresh buffer. The drug release was determined spectro photometrically after dilution by measuring the absorbance at $239.2 \mathrm{~nm}$ using the respec- tive receptor medium as a blank, to calculate the amount of drug released from the nano particles.

\section{Transmission Electron Microscopy determination}

An external morphology of prepared NLC in liquid state was determined using transmission electron microscopy. A sample of the NLC was placed in a copper grid. Digital Micrograph and Soft Imaging Viewer software were used to capture the image and analysis the particle size. $^{13}$ 


\begin{tabular}{|c|c|c|c|c|c|c|}
\hline \multicolumn{7}{|c|}{ Table 1: Formulation Design of NLCs } \\
Formulation & $\begin{array}{c}\text { Drug: lipid } \\
\text { ratio }\end{array}$ & Drug (mg) & Stearic acid (mg) & $\begin{array}{c}\text { Compritol ATO } \\
\mathbf{8 8 8}(\mathbf{m g})\end{array}$ & $\begin{array}{c}\text { Oleic acid } \\
\text { (mg) }\end{array}$ & $\begin{array}{c}\text { Poloxamer } \\
\mathbf{1 8 8}(\%)\end{array}$ \\
\hline F1 & $1: 1$ & 5.0 & 5 & -- & 5 & 1.0 \\
\hline F2 & $1: 3$ & 5.0 & 15 & -- & 15 & 1.0 \\
\hline F3 & $1: 6$ & 5.0 & 30 & -- & 30 & 1.0 \\
\hline F4 & $1: 9$ & 5.0 & 45 & -- & 45 & 1.0 \\
\hline F5 & $1: 1$ & 5.0 & -- & 5 & 5 & 1.0 \\
\hline F6 & $1: 3$ & 5.0 & -- & 15 & 15 & 1.0 \\
\hline F7 & $1: 6$ & 5.0 & -- & 30 & 30 & 1.0 \\
\hline F8 & $1: 9$ & 5.0 & -- & 45 & 45 & 1.0 \\
\hline
\end{tabular}

Drug: Rosuvastatin, Solid lipid: Stearic acid and Compritol ATO 888, liquid lipid: Oleic acid, surfactant: Poloxamer 188

\section{Table 2: Particle Size, Polydispersity Index, \% Drug Content, \% Entrapment Efficiency and} Zeta Potential of NLC Formulation F1 To F8

\begin{tabular}{|c|c|c|c|c|c|}
\hline Formulation & $\begin{array}{c}\text { Particle size* } \\
\text { (nm) }\end{array}$ & PDI $^{*}$ & $\begin{array}{c}\text { Drug content* } \\
\mathbf{( \% )}\end{array}$ & $\begin{array}{c}\text { Entrapment } \\
\text { efficiency* } \\
\mathbf{( \% )}\end{array}$ & $\begin{array}{c}\text { Zeta potential } \\
(\mathbf{m V})\end{array}$ \\
\hline F1 & $405.8 \pm 0.23$ & $0.83 \pm 0.23$ & $86.81 \pm 0.73$ & $68.7 \pm 0.62$ & $-27.6 \pm 0.44$ \\
\hline F2 & $289.3 \pm 0.30$ & $0.25 \pm 0.32$ & $94.77 \pm 0.72$ & $89.1 \pm 0.20$ & $-43.28 \pm 1.62$ \\
\hline F3 & $273.3 \pm 0.35$ & $0.22 \pm 0.18$ & $96.59 \pm 0.49$ & $86.7 \pm 0.55$ & $-50.6 \pm 0.46$ \\
\hline F4 & $314.9 \pm 0.11$ & $0.37 \pm 0.62$ & $93.86 \pm 0.65$ & $82.2 \pm 0.27$ & $-34.5 \pm 0.9$ \\
\hline F5 & $785.9 \pm 0.11$ & $0.91 \pm 0.32$ & $83.18 \pm 0.37$ & $59.12 \pm 0.12$ & $-20.5 \pm 1.5$ \\
\hline F6 & $776.6 \pm 0.57$ & $0.90 \pm 0.24$ & $85.45 \pm 0.23$ & $66.05 \pm 0.38$ & $-32.4 \pm 0.4$ \\
\hline F7 & $542.9 \pm 0.05$ & $0.46 \pm 0.12$ & $87.72 \pm 0.35$ & $72.80 \pm 0.50$ & $-31.65 \pm 0.55$ \\
\hline F8 & $565.4 \pm 0.69$ & $0.50 \pm 0.78$ & $89.54 \pm 0.23$ & $75.65 \pm 0.42$ & $-25.1 \pm 1.7$ \\
\hline
\end{tabular}

Results are expressed as mean \pm standard deviation (mean $\pm S D) n=3$

\begin{tabular}{|c|c|c|c|}
\hline \multicolumn{2}{|c|}{ Table 3: Pharmacokinetic Parameter of Marketed Product and Optimized } \\
Formulation F3 \\
\hline Formulation & $\begin{array}{c}\mathbf{C}_{\max } \\
(\boldsymbol{\mu g} / \mathbf{m l})\end{array}$ & $\begin{array}{c}\mathbf{T}_{\max } \\
(\mathbf{h})\end{array}$ & $\begin{array}{c}\text { AUC }_{\text {o-t }} \\
(\boldsymbol{\mu g} / \mathbf{m l} . \mathbf{h})\end{array}$ \\
\hline Marketed product & 6.391 & 0.5 & 81.4 \\
\hline Optimized formulation (F3) & 13.839 & 8 & 165.16 \\
\hline
\end{tabular}

\section{Stability study}

The stability studies were conducted according to ICH guidelines. ${ }^{14}$ The stability of optimized formulation $\mathrm{F} 3$ was determined by keeping the formulation at $25^{\circ} \mathrm{C} \pm 2^{\circ} \mathrm{C} / 65 \% \mathrm{RH}$ and $4^{\circ} \mathrm{C} \pm 2^{\circ} \mathrm{C} / 65 \% \mathrm{RH}$. The samples were tested after $15^{\text {th }}$ and $30^{\text {th }}$ day for $\%$ entrapment efficiency and in vitro drug release.

\section{In vivo study}

Ethical clearance was obtained from the Institutional Animal Ethics Committee (Resolution No: KLECOP/ IAEC/Res.22-10/10/2015) prior to the beginning of animal study.
Six healthy male wistar rats weighing 180-200 g were obtained and divided into 2 groups each group containing three rats. ${ }^{15,16}$ Group1 received marketed product in normal saline through oral route while Group 2 received NLC formulation F3 in normal saline. After 0.5, 2.0, 4.0, 6.0, 8.0, 10.0, 12.0 and $24.0 \mathrm{~h}, 0.5 \mathrm{ml}$ blood was collected from eye by retro-orbital puncture into eppendorf tube containing $10 \mu \mathrm{l}$ of EDTA and centrifuged at $5000 \mathrm{rpm}$ for 20 mins, Supernant plasma was collected, and acetonitrile was added for precipitating the plasma proteins and vortexed for $1 \mathrm{~min}$ and centrifuged at 5000 rpm for 15 min. Supernant solution was collected and filtered through $0.45 \mu \mathrm{m}$ membrane into clean vials and 
analyzed through HPLC. The pharmacokinetic parameters were calculated by applying trapezoidal method. The HPLC method was validated before carrying the analysis of the drug. The HPLC system composed of Thermo hypersil $\mathrm{C}_{18}$ column $250 \times 4.6 \mathrm{~mm}, 5 \mu \mathrm{m}$ diameter was used for separation. The mobile phase containing $0.1 \%$ Disodium hydrogen phosphate and Acetonitrile in the ratio of $50: 50(\mathrm{v} / \mathrm{v})$ was delivered at a flow rate of $0.7 \mathrm{ml} / \mathrm{min}$ and the elution was monitored at $240 \mathrm{~nm}$. Injection volume was $20 \mu \mathrm{l}$ and pressure of $52 \mathrm{~kg} / \mathrm{cm}^{2}$.

\section{RESULTS AND DISCUSSION}

The present study was focused to develop Nano structured Lipid carrier formulations. Preliminary studies were performed to optimize the concentrations of lipid carriers stearic, Compritol ATO 888, Oleic acid and surfactant Poloxamer 188. The NLCs formulations F1 to F8 were successfully prepared using the lipid carriers, surfactant and drug proportions by high shear homogenisation and ultra sonication method as shown in Table 1 and Figure 1 respectively. All the formulations were subjected for evaluation.

\section{Particle size and Poly dispersity index}

Particle size data for the Nano structured lipid carrier of Rosuvastatin using stearic acid and Compritol ATO 888 in combination with Oleic acid are shown in Table 2. The particle size of formulation F1 to F4 is in the range of $273.26 \mathrm{~nm}$ to $405.8 \mathrm{~nm}$ containing drug: lipid ratio from 1:1 to $1: 4$ of stearic acid as a solid lipid. Formulation F5 to F8 was having particle size in the range of $542.9 \mathrm{~nm}$ to $785.9 \mathrm{~nm}$ containing drug: lipid ratio from 1:1 to 1:4 of Compritol ATO 888 as a solid lipid. The optimum concentration of drug: lipid ratio was found to be 1:3; further increase in concentration of lipid ratio there is increase in particle size. Stearic acid was found to be optimum lipid for NLC preparation compared with Compritol due to maximum solubility of Rosuvastatin in stearic acid. The mean particle size of NLC F3 was observed to be $273.3 \mathrm{~nm}$ with least particle size compared with other formulations. The mean Poly dispersity index value of drug loaded NLC formulations $F 1$ to $F 8$ varied in the range of 0.22 to 0.91 as shown in Table 2.

\section{Drug content}

Drug content for formulation F1 to F4 with stearic acid $\&$ Oleic acid were found to be in the range of $86.81 \%$ to $96.59 \%$, while formulations F5 to F8 with Compritol ATO 888 \& Oleic acid were found to be in the range of
$83.18 \%$ to $89.54 \%$ as shown in Table 2. Formulation F3 with stearic acid as solid lipid showed maximum drug content $96.59 \%$.

\section{Percentage entrapment efficiency}

NLC formulation F1 to F4 showed percent encapsulation efficiency of $68.7 \%$ to $89.2 \%$. Encapsulation efficiency increased with increase in the concentration of solid lipid up to $30 \mathrm{mg}$ further there was decrease in the entrapment efficiency with increase in solid lipid concentration at $45 \mathrm{mg}$. NLC formulation F5 to F8 showed percent encapsulation efficiency of $59.12 \%$ to $75.6 \%$ for concentration of lipids 5 to $45 \mathrm{mg}$ respectively, corresponding with increase in the concentration of lipid the $\%$ entrapment efficiency also increased.

\section{Zeta potential}

Zeta potential for formulations F1 to F8 was between -20.5 to $-50.6 \mathrm{mv}$. Formulation F3 showed zeta potential of $-50.6 \mathrm{mv}$ which indicate optimum for better stability. Further formulation F3 was selected as optimized formulation based on the mean particle size of $213.26 \mathrm{~nm}$, poly dispersity index of 0.22 , and entrapment efficiency of $89.1 \%$ and zeta potential of 50.6. Further formulation F3 was subjected for TEM studies, stability study and In-vivo studies.

\section{In vitro release study}

The In-vitro release of formulation F1 to F4 at the end of $12 \mathrm{hrs}$ was found to be in range $67.65 \%$ to $76.22 \%$ as shown Figure 2 and for formulation F5-F8 was found to be in range $61.16 \%$ to $67.36 \%$ as shown Figure 3 . It was observed that $\mathrm{F} 3$ having smallest mean particle size $273.3 \mathrm{~nm}$ showed maximum release at the end of $12 \mathrm{hrs}$. It was observed that as the particle size increased, the release rate decreased. In vitro release profile of pure drug showed the drug release within $4 \mathrm{hrs}$, whereas the optimized formulation F3 showed drug release of $76.22 \%$ upto $12^{\text {th }} \mathrm{h}$ which indicates prolonging the drug release of nano formulation as shown in Figure 2. TEM images of the optimized formulation F3 showed that the formulations were in nano size range as shown in Figure 4. Stability study showed no significant change observed in the $\%$ entrapment efficiency and in-vitro drug release as conducted at an interval of 10 days for 1 month at $4 \pm 2^{\circ} / 65 \%$ RH.

\section{In vivo study}

The study was carried out on male Wistar rats to compare plasma concentration of optimized formulation F3 with that of Marketed product given orally with normal saline. Marketed product showed $\mathrm{AUC}_{0-\mathrm{t}}$ of $81.4 \mu \mathrm{g} / \mathrm{ml}$. hr whereas optimized formulation F3 showed 165.16 
$\mu \mathrm{g} / \mathrm{ml} . \mathrm{hr}$ as shown in Table 3. Rosuvastatin loaded Nano structured lipid carrier were able to improve bioavailability with 2 folds as compared to marketed product and able to provide sustained release of drug for prolong period of time as shown in Figure 5.

\section{CONCLUSION}

In the present study, Rosuvastatin loaded Nano structured lipid carrier were successfully prepared by High shear homogenisation followed by Ultra sonication method. The mean particle size of prepared NLC decreased with increase in lipid concentration up to certain concentration range and further increase in concentration resulted in increase in mean particle size. In vitro drug release of optimized formulation showed sustained release profile with $76.22 \%$ release up to $12 \mathrm{~h}$. In this study two solid lipids (stearic acid and Compritol ATO 888) were compared with liquid lipid in different concentration in order to select suitable solid lipid for Rosuvastatin to achieve particle size in nano range. Based on the results of all the parameters, Stearic acid was found to be best suitable Solid lipid for Rosuvastatin to achieve particle size in nano range. In vivo study was performed in male Wistar rats and subjected to the pharmacokinetic study and it was found that Nanostructure lipid carrier were able to improve bioavailability with two folds compared to marketed conventional tablet and able to provide sustained release of drug for prolong period of time.

\section{ACKNOWLEDGEMENT}

The authors are thankful to Cadila Health Care Ltd, Goa for providing gift sample of Rosuvastatin. The authors are also thankful to the Principal, KLEU College of Pharmacy, Belagavi and Dr. PK Basic Science Research centre, Belagavi for providing laboratory and necessary facilities to carry out research work.

\section{CONFLICT OF INTEREST}

There are no conflicts of interest

\section{ABBREVIATION USED}

NLC: Nano structured lipid carrier; TEM: transmission electron microscopy; HPLC: High performance liquid chromatography

\section{REFERENCES}

1. Iqbal MA, Md S, Sahni J K, Baboota S, Dang S, Ali J. Nanostructured lipid carriers system: Recent advances in drug delivery. Journal of Drug Targeting, 2012;20(10):813-30. http://dx.doi.org/10.3109/1061186X.2012.716845 PMid:22931500.

2. Kush A, Kumar S M. Development of Lacidipine loaded nanostructured lipid carriers (NLCs) for bioavailability enhancement. International Journal of Pharmaceutical and Medicinal Research. 2014;2(2):50-7.

3. Rosuvastatin [internet] Available from: http://www.drugbank.ca/drugs/ DB01098.

4. Emami J, Rezazadeh M, Varshosaz J, Tabbakhian M, Aslani A. Formulation of LDL targeted nanostructured lipid carriers loaded with paclitaxel: A detailed study of preparation, freeze drying condition, and in vitro cytotoxicity. Journal of Nanomaterials, 2012;10 http://dx.doi.org/10.1155/2012/358782

5. Cortese F, Gesualdo M, Cortese A, Carbonara S, Devito F, et al. Rosuvastatin: Beyond the cholesterol-lowering effect. Pharmacological Research. 2016;107(5):1-18. http://dx.doi.org/10.1016/j.phrs.2016.02.012; PMid:26930419.

6. Rizwanullah M, Amin S, Ahmad J. Improved pharmacokinetics and antihyperlipidemic efficacy of Rosuvastatin-loaded Nanostructured lipid carriers. J Drug Target. 2016;22(6):1-17 http://dx.doi.org/10.1080/ 1061186X.2016.1191080 ; PMid:27186665.

7. Priyanka K, Satha IAAH. Preparation and Evaluation of Montelukast Sodium loaded Solid Lipid Nanoparticles. Journal of Young Pharmacists, 2012; 4(3):129-37. http://dx.doi.org/10.4103/0975-1483.100016; PMid:23112531 PMCid:PMC3483522

8. Dandagi PM, Dessai GA, Gadad AP, Desai VB. Formulation and evaluation of Nanostructured Lipid Carrier (NLC) of Lornoxicam. International Journal of Pharmacy and Pharmaceutical Sciences, 2014;6(2):73-7.

9. Srinath B, Jagannathan KS, Jayaveera KN. Development and characterization of colloidal carrier system for oral delivery of serratiopeptidase. International Journal of Pharmaceutical Sciences. 2013;3(3):248-53.

10. Kaur S, Rao R, Hussain A, Khatkar S. Preparation and characterization of Rivastigmine Loaded Chitosan nano particles. Journal of Pharmaceutical Sciences and Research. 2011;3(5):1227-32.

11. Sanyog J, Amit KJ, Nitin KS, Chandraiah G, Raman PS. The effect of the oral administration of polymeric nanoparticles on the efficacy and toxicity of tamoxifen. Biomaterials. 2011;32:503-15. http://dx.doi.org/10.1016/j. biomaterials. 2010.09.037 ; PMid:20934747

12. Motwani SK, Chopra S, Talegaonkar S, Kohli K, Ahmad FJ, Khar RK. Chitosan - sodium alginate nanoparticles as submicroscopic reservoirs for ocular delivery: Formulation, optimisation and in vitro characterization. European Journal Pharmaceutical Biopharmaceutics. 2008;68(3):513-25.; PMid: 17983737

13. Lobo MS, Costa P. Modeling and comparison of dissolution profiles. European Journal of Pharmaceutical Sciences. 2001;13(2):123-33. http:// dx.doi.org/10.1016/S0928-0987(01)00095-1

14. Peng Liu, Xinyu R, Johanna L, Bert-van V, Juhu $\mathrm{K}$, Jouni $\mathrm{H}$ et al. Nanosuspension of poorly soluble drugs: preparation and development by wet milling. International Journal of Pharmaceutics, 2014;11(1):215-22.

15. Kumar TR, Shitut NR, Kumar PK, Menon CA, Venkata V, Kumar P, et al. Determination of Rosuvastatin in rat plasma By plasma; Validation and its application to pharmacokinetic studies. Biomedical Chromatography. 2006;20(9):881-8 http://dx.doi.org/10.1002/bmc.611; PMid:16389642.

16. Gurmeet C, Chandraprakash J, Saurabh KB. Development and validation of RP-HPLC method for the determination of Atomoxetine Hydrochloride in Pharmaceutical Dosage Forms. 2011;3(4):275-9. 


\section{SUMMARY}

- The NLCs formulations F1 to F8 were successfully prepared, the mean particle size of NLC F3 was observed to be $273.3 \mathrm{~nm}$ with least particle size compared with other formulations. The mean Polydispersity index value of drug loaded NLC formulations F1 to F8 varied in the range of 0.22 to 0.91 . Drug content for Formulation F3 with stearic acid as solid lipid showed maximum drug content $96.59 \%$.

- NLC formulation F1 to F4 showed percent encapsulation efficiency of $68.7 \%$ to $89.2 \%$. Encapsulation efficiency increased with increase in the concentration of solid lipid up to $30 \mathrm{mg}$ further there was decrease in the entrapment efficiency with increase in solid lipid concentration at $45 \mathrm{mg}$. NLC formulation F5 to F8 showed percent encapsulation efficiency of $59.12 \%$ to $75.6 \%$ for concentration of lipids 5 to $45 \mathrm{mg}$ respectively, corresponding with increase in the concentration of lipid the \% entrapment efficiency also increased. Zeta potential for Formulation F3 showed zeta potential of $-50.6 \mathrm{mv}$ which indicate optimum for better stability.

- In vitro release profile of pure drug showed the drug release within $4 \mathrm{hrs}$, whereas the optimized formulation F3 showed drug release of $76.22 \%$ upto $12^{\text {th }} \mathrm{h}$ which indicates prolonging the drug release of nano formulation. TEM images of the optimized formulation F3 showed that the formulations were in nano size range.

- In vivo study showed AUCO-t of $81.4 \mu \mathrm{g} / \mathrm{ml}$.hr for marketed formulation whereas optimized formulation F3 showed $165.16 \mu \mathrm{g} / \mathrm{ml}$.hr, improving bioavailability with two folds as compared to marketed product and able to provide sustained release of drug for prolong period of time.

\section{About Authors}

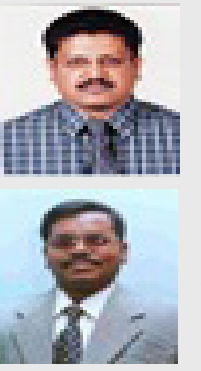

Anand Panchakshari Gadad: Is a Professor and Head, Department of Pharmaceutics, Faculty of Pharmacy, KLE University, Belagavi. He is working on areas of targeted drug delivery system viz., Gastroretentive drug delivery system, Polymeric nanoparticles, enhancing solubility of poorly soluble drugs, etc.

Panchaxari Mallappa Dandagi: Is a Professor, Department of Pharmaceutics, Faculty of Pharmacy, KLE University, Belagavi. He is working on areas of targeted drug delivery system viz., Colon drug delivery system using $\mathrm{pH}$ dependent polymers and also Ocular drug delivery system through Nano and microspheres.

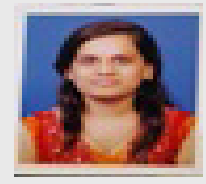

Swetha Gangadhar Tigadi: Obtained her post-graduate in 2016 from Dept. of Pharmaceutics, Faculty of Pharmacy, KLE University, Belagavi. She worked in the area of Nanostructured Lipid carrier to enhance the drug solubility \& bioavailability.

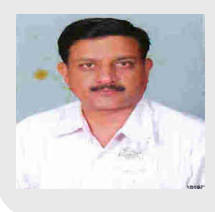

Uday Baburao Bolmal: Is an Assistant Professor, Department of Pharmaceutics, Faculty of Pharmacy, KLE University, Belagavi. He is working on biosynthesis of Biosurfactants from the bacteria, solubility enhancement techniques using Biosurfactants. 